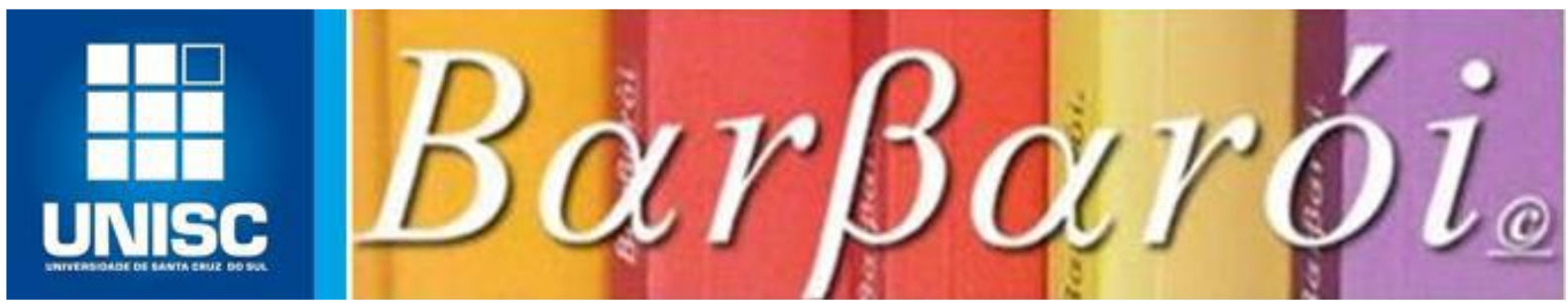

\title{
MOVIMENTO FEMINISTA E ANTIMANICOMIAL: UMA ANÁLISE DAS LUTAS POR DIREITOS EM UMA SOCIEDADE CAPITALISTA-PATRIARCAL
}

\author{
DOI: http://dx.doi.org/10.17058/barbaroi.v0i58.15204 \\ $*$ \\ Alessandra Rodrigues Sardeto \\ Centro Universitário Ingá - UNINGÁ - Brasil \\ Natalia Bazarghi \\ Pontifícia Universidade Católica do Paraná - PUCPR-Brasil
}

Daniele Andrade Ferrazza

Universidade Estadual de Maringá - UEM - Brasil

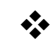

\section{Resumo}

O presente artigo tem como objetivo traçar um paralelo entre o movimento feminista e o movimento antimanicomial procurando pontos de convergência e divergência entre ambos, a fim de verificar suas possíveis articulações. Para isso, por meio de revisão bibliográfica, buscase contextualizar os movimentos sociais e realizar a análise histórica de ambos, afim de esclarecer suas motivações, formas de atuação na luta por direitos e atendimento de demandas dos sujeitos envolvidos com pretensões de alcançar transformações sociais. Dessa forma, o material discute as confluências e divergências entre o movimento feminista e antimanicomial, na tentativa de ampliar e construir o debate acadêmico acerca do assunto, que se transforma diariamente, de modo democrático e dialético. À guisa de conclusão, considera-se a necessidade de constituir novas formas de pensar sobre nossa condição histórica, com intuito de que isso possibilite a criação de estratégias de reinvenção e recriação constante de coletivos de luta e que promovam movimentos de resistências aos poderes instituídos que submetem mulheres e sujeitos em sofrimento psíquico, com objetivos de constituir mudanças e responsabilização social para que os absurdos tolerados por parcela considerável da sociedade não se reproduzam. Palavras-chave: movimentos sociais; feminismos; luta antimanicomial; normatização da vida.

\section{Introdução}

O modelo capitalista e patriarcal da sociedade atual não é organizado para considerar as contradições da vida e tampouco os diferentes modos de ser e estar no mundo (RAGO, 2019). Por conta disso, os movimentos sociais e seus sujeitos coletivos organizam-se em grupos para resistir e alterar a lógica política, o sistema cultural e a vida cotidiana de pessoas que 
reivindicam democraticamente seus direitos, ao mesmo tempo em que lutam contra o preconceito, a normatização e os processos de estigmatização (COIMBRA; NASCIMENTO, 2012; GOHN, 2011; 2003).

Conscientes e orientados por princípios valorativos comuns, esses grupos se articulam e se direcionam de modo contínuo e plástico, conforme o contexto e as transformações de seu tempo, com intuito de conquistar direitos e garantir o exercício da cidadania. Na sociedade pósindustrial contemporânea, as ruas tornam-se palco, e ao mesmo tempo personagem das manifestações coletivas, permeadas por mensagens que falam sobre os atores sociais, seus anseios e sentimentos. Tais mobilizações são capazes, inclusive, de alcançar a construção de políticas públicas como as de Saúde, Educação e Assistência Social (GOHN, 2011; SADER, 1995).

Neste estudo, coloca-se em evidência a história, formação e objetivos de dois movimentos sociais: o Movimento Feminista e o Antimanicomial. Dessa maneira, considerando o atravessamento do machismo no processo de manicomialização das mulheres, o presente trabalho tem como objetivo traçar um paralelo entre os dois movimentos, procurando pontos de convergência e divergência entre ambos, a fim de verificar suas possíveis articulações.

Para compreender as mobilizações de sujeitos coletivos em suas vozes que ecoam pelas ruas, o presente estudo, ancorado em uma revisão bibliográfica não sistemática, em um primeiro momento conceitua os movimentos sociais à luz dos estudos da Psicologia Social. Em um segundo momento, traça o panorama histórico - em especial a partir do século XX no contexto mundial e brasileiro - sobre os objetivos e as características do movimento de mulheres por meio dos estudos feministas de autoras brasileiras e estrangeiras. Em um terceiro momento, o mesmo processo é feito para compreender o movimento antimanicomial, tomando como base autores da perspectiva da Atenção Psicossocial no campo da Saúde Mental. E, finalmente, em um quarto momento, diante das informações e ideias levantadas, realiza-se uma análise sobre possíveis convergências e divergências dos movimentos feministas e antimanicomiais.

Em busca de uma sociedade mais equitativa, com maior entendimento a respeito das diferenças e semelhanças que nos torna humanos, refletir sobre o assunto é parte do processo de novas práticas. Então, promover o diálogo teórico sobre a temática é necessário para que o debate ganhe força, seja nos movimentos sociais, na academia, nos espaços de formação ou nos dispositivos jurídicos, educacionais, de saúde e de assistência social. 


\section{Breves apontamentos sobre os movimentos sociais}

A luta de grupos que, coletivamente, vem à público problematizar, questionar, 'dar voz' aos aspectos da realidade que destoam de desejos e de necessidades essenciais à vida humana são entendidos por movimentos sociais. Mobilizações que surgem na contramão do modelo hegemônico dominante ao politizar condições de exclusão e opressão, refazem as fronteiras do político e da democracia, e visam superar modelos institucionais, partidários e Estatais (GONH, 2003). Nesse sentido, os Movimentos Sociais podem ser compreendidos por: "ações sociais coletivas de caráter sociopolítico e cultural que viabilizam formas distintas de a população se organizar e expressar suas demandas". (GONH, 2011, p. 335). Para Scherer-Warren (1989, p. 20), trata-se de:

[...] uma ação grupal para transformação (a práxis) voltada para a realização dos mesmos objetivos (o projeto), sob a orientação mais ou menos consciente de princípios valorativos comuns (a ideologia) e sob uma organização diretiva mais ou menos definida (a organização e sua direção).

Considerando o contexto histórico, social e político é possível dizer que a sociedade atual se organiza segundo a ótica de uma política neoliberal, pautada em valores da meritocracia, do individualismo e do privativismo. Tais características se distanciam, muitas vezes, do engajamento crítico político-social (COIMBRA; NASCIMENTO, 2012). Assim, consequentemente, cria-se uma postura em que algumas realidades não são enfrentadas ou contestadas, afirmando mais uma vez que: "as pessoas se fazem pelo seu próprio esforço individual e a cidadania é aferida pela integração individual ao mercado.” (DIAZ, 2008, p. 181).

Os movimentos sociais e seus sujeitos coletivos ${ }^{1}$ são considerados a partir da intersecção da sociedade com a política e não buscam o modelo de sociedade perfeita, mas lutam pela democratização das relações sociais (DIAZ, 2008). Os movimentos são expressões de resistência a diversas formas de opressão, com objetivos de constituir lutas pela construção de algo novo e libertador, para tanto as mobilizações tendem a proporcionar o diagnóstico da realidade social na construção de ações coletivas que devem se disseminar como enfrentamento à exclusão, à discriminação e ao preconceito (GONH, 1997). Nesse sentido, é possível observar que as mobilizações alteram não só a lógica política, mas também operam em fissuras nos discursos hegemônicos, alteram a vida cotidiana das pessoas e produzem "revoluções moleculares" (COIMBRA; NASCIMENTO, 2012).

\footnotetext{
${ }^{1}$ Para Sader (1995), sujeitos coletivos são uma coletividade em que se elabora uma identidade e se organizam práticas por meio das quais seus membros pretendem defender interesses e expressar suas vontades, constituindose nessas lutas.
} 
Segundo Tilly (2010, p.149), “os movimentos sociais surgem no final do século XVIII, como elaborações coletivas de reivindicações conflitantes com os interesses de algum grupo". $\mathrm{Na}$ sociedade industrial do século XIX, o aumento do desemprego, das baixas condições salariais e da marginalização e pauperização da população, impulsionou grupos de operários a se organizarem contra a burguesia, pela reivindicação de seus direitos trabalhistas e pelas mudanças no âmbito da estratificação social (JESUS, 2012).

No século XX, os novos movimentos sociais atingem seu ápice nas movimentações do denominado "Maio de 1968", mobilização francesa que repercute na Europa e nos Estados Unidos, reverberando no Brasil com maior intensidade na década de 1970 (ZAPPA; SOTO, 2018). Na sociedade pós-industrial, os movimentos sociais estão inter-relacionados aos aspectos subjetivos, afetivos e culturais, atrelados às dimensões da solidariedade, do conflito e da mudança e/ou ruptura com a lógica do sistema social. No contexto brasileiro do século XX: “[...] os movimentos originam-se da resistência ao regime autoritário dos anos 70 e sua construção coletiva se fez na forma de teia ou rede, articulando-se com outras organizações, tais como sindicatos e partidos políticos". (DIAZ, 2008, p. 181).

A partir da década de 1980 houve a incorporação dos movimentos sociais no cenário político e a construção de espaços plurais de representação dos sujeitos coletivos. Com o fim da ditadura no país, o processo de redemocratização inseriu novos atores sociais, assim como uma nova agenda política nas instituições brasileiras (SADER, 1995). Dessa forma, os grupos levaram à público sua condição de pauperização, desigualdade e injustiça que antes limitava-se à esfera privada, principalmente, questionando sua exclusão dos arranjos políticos.

Na década 1990, o cenário é de redefinição do papel do Estado com o qual os sujeitos coletivos dos movimentos sociais estabelecem novas relações. "Ao invés de práticas clientelistas e assistencialistas, criam-se vários fóruns de negociação e participação, onde as demandas populares tomam forma nas políticas públicas”. (DIAZ, 2008, p.183). Sendo assim, minimiza-se a redução da sociedade civil a meros consumidores de mercado, e a cidadania é ampliada em oposição ao neoliberalismo, o qual defende o Estado mínimo e a despolitização da questão dos direitos.

Os novos movimentos sociais rompem com os paradigmas tradicionais e por meio deles observa-se que a natureza da sociedade civil é contraditória e heterogênea, com uma pluralidade de interesses, o que pode gerar conflitos em seu interior. Além disso, se diferenciam dos antigos movimentos, que se concentravam mais nas organizações do trabalho e no controle do poder 
econômico burguês, por abarcar as dimensões subjetivas, afetivas e culturais como indissociáveis do contexto sócio-histórico.

As mobilizações da sociedade civil organizada, como as marchas, paradas e ocupações, podem ser definidas como ritos, uma comunicação simbólica permeada de mensagens metafóricas que falam sobre os atores que os realizam, bem como seus pensamentos e sentimentos, fazendo com que eles suspendam temporariamente sua rotina e realizem performances de identidades e papéis sociais não-hegemônicos nas ruas. A exemplo disso, pôde-se observar ao longo da história recente brasileira, a Marcha das Vadias, a Marcha das Margaridas, a Parada do Orgulho LGBT, a Marcha Zumbi, entre inúmeras outras que se estabelecem e se fortalecem no contexto brasileiro de luta e reivindicações (JESUS, 2012).

Em uma perspectiva psicossocial, considera-se que as pessoas se organizam em grupos e movimentos para protestarem em nome de uma causa comum, muitas vezes sacrificando seu conforto pessoal, por várias razões, que podem estar fundamentadas em diferentes fatores, entre eles: sentimento de injustiça, eficácia de grupo, identidade social e afetividade.

A partir disso, neste trabalho, serão abordados em especial dois movimentos sociais marcados pela desconstrução de paradigmas dominantes na busca por um novo olhar sobre o lugar social da loucura, proposto pela luta antimanicomial, e uma proposta de transformação da desigualdade de gênero almejada pelas mulheres, por meio do movimento feminista.

\section{Movimento feminista: constituição histórica de lutas e resistências}

O movimento feminista é um movimento social, político e cultural que busca reivindicar e lutar pelos direitos das mulheres, a fim de que estas não sejam acuadas por diversas formas de opressão social. Para isso, o feminismo produz reflexões críticas sobre concepções teóricas e práticas no enfrentamento aos discursos e às práticas machistas, sexistas, misóginas e homofóbicas (bell hooks, 2018). Assim, paulatinamente, no decorrer da história ocidental as mulheres rejeitaram sua condição de 'segundo lugar' no mundo e lutaram por liberdade e pela conquista de espaços em âmbitos políticos e sociais com intuito de fazer ecoar suas vozes (CARNEIRO, 2003).

Foram diferentes gerações de mulheres que lutaram por direitos e que constituiriam as diversas fases, ou as denominadas "ondas", do movimento feminista em épocas distintas marcadas historicamente pelas necessidades políticas, sociais e econômicas de cada período. Nesse contexto, é necessário compreender que não existe na atualidade um movimento feminista "unívoco e totalizante", mas diversas mobilizações feministas que ora se configuram 
em diálogo com diferentes perspectivas teóricas e ora se estruturam com diferentes demandas na intersecção entre gênero, raça, classe social e sexualidade (NARVAZ; KOLLER, 2006). Estes movimentos ganham contornos específicos influenciados pela orientação sexual, por aspectos étnicos e de plasticidade de aparências e idades (TIBURI, 2018).

A primeira geração de mulheres organizadas para os enfrentamentos contra a opressão de gênero e a favor da igualdade de direitos civis, educativos e políticos se estabeleceu a partir das últimas décadas do século XIX, principalmente, nos Estados Unidos e em países da Europa. O momento foi caracterizado pelo surgimento do movimento feminista que dentre diversas reivindicações lutavam pelo direito ao voto, por melhores condições de trabalho e pela conquista de acesso à educação de mulheres (NARVAZ; KOLLER, 2006).

No Brasil, a 'primeira onda' do movimento feminista se constituiu no início do século XX. Lideradas por Bertha Luz, uma das fundadoras da Federação Brasileira pelo Progresso Feminino, algumas mulheres brasileiras se mobilizam e conquistam o direito ao voto no ano de 1932. Junto às primeiras mobilizações das sufragistas brasileiras, há o surgimento do movimento das operárias de ideologia anarquista, a denominada "União das Costureiras, Chapeleiras e Classes Anexas", que refletiam sobre a condição das mulheres nas fábricas e oficinas e lutavam por direitos trabalhistas, igualdade salarial e por melhores condições nos espaços de trabalho (PINTO, 2010).

Campoi (2019) ressalta que o feminismo sufragista, em sua vertente liberal, foi liderado por mulheres brancas (urbanas e alfabetizadas) das classes médias, e que pode ser compreendido como um movimento internacionalista que se utilizou da imprensa como veículo de divulgação de suas ideias e reivindicações. Enquanto isso, existiam outras frentes como as vinculadas às ideias anarquistas e socialistas, em que se destaca: "a luta pelo reconhecimento de direitos e oportunidades iguais para mulheres e homens, enfim, pela igualdade entre os seres humanos". (CAMPOI, 2019, p. 11).

Segundo Pinto (2010), seja na Europa, Estados Unidos ou no Brasil, o movimento pertencente à primeira onda feminista perdeu força a partir da década de 1930 e voltou a se fortalecer na emblemática década de 1960. Este foi um momento de transformações impactantes no cenário do mundo ocidental, marcado pela Guerra do Vietnã, pelo Movimento Hippie, pelas mobilizações de Maio de 68, pelo Movimento Negro, pelo lançamento da pílula anticoncepcional, pela revolução musical com Beatles e Rolling Stones e pelo lançamento de livros emblemáticos do novo feminismo: “A Mística feminina” de Betty Friednan e "O Segundo Sexo" de Simone de Beauvoir (PINTO, 2010). Em uma nova frente de luta, denominada como 
a 'segunda onda do feminismo', as mulheres problematizavam as temáticas ligadas ao corpo e, imersas no contexto dos movimentos da contracultura, as feministas questionavam a reprodução (quase compulsória), a sexualidade e a heteronormatividade (CAMPOI, 2019).

\begin{abstract}
O feminismo aparece como um movimento libertário, que não quer só espaço para a mulher - no trabalho, na vida pública, na educação -, mas que luta, sim, por uma nova forma de relacionamento entre homens e mulheres, em que esta última tenha liberdade e autonomia para decidir sobre sua vida e seu corpo. Aponta, e isto é o que há de mais original no movimento, que existe uma outra forma de dominação - além da clássica dominação de classe -, a dominação do homem sobre a mulher - e que uma não pode ser representada pela outra, já que cada uma tem suas características próprias. (PINTO, 2010, p.16).
\end{abstract}

O Brasil, por sua vez, teve uma dinâmica lenta de mobilizações quando comparada ao cenário mundial, uma vez que, após o conturbado movimento político do início dos anos de 1960, instaurou-se o golpe militar que atingiria seu rigor no ano de 1968, no governo do general Arthur Costa e Silva (1899-1969), com o decreto do Ato Institucional n5 (AI-5). Aquele seria os ‘Anos de Chumbo', período mais radical do governo militar, cujas práticas de tortura, prisões políticas, assassinatos e desaparecimento de pessoas, disseminaria o terror pela sociedade brasileira (COIMBRA; NASCIMENTO, 2012). Assim, enquanto os países da Europa e os Estados Unidos aprofundavam-se nas mobilizações políticas e nas discussões identitárias, o Brasil, nos anos de regime ditatorial, sofria a repressão total da luta política legal.

De acordo com Pinto (2010, p. 17), naquele contexto, limitado pelas condições vivenciadas, ocorreram as primeiras manifestações feministas no Brasil na década de 1970, ainda que o governo enxergasse as feministas como "políticas e moralmente perigosas". As militantes que resistiam aos anos de chumbo colaboraram para a criação de um movimento social que até então atuava clandestinamente, mas que ainda em anos ditatoriais existiria de modo aberto. Vale ressaltar que o feminismo brasileiro se chamava "movimento de mulheres" (CARNEIRO, 2003), organizadas nas camadas da classe média branca e, somente aos poucos, o movimento articulou-se com as camadas populares e organizações de bairro, constituindo-se em um movimento interclasses na luta por direitos e pela redemocratização do país (SARTI, 2004). O movimento feminista no Brasil teve matizes próprias, uma vez que ganhou a política de alianças entre o feminismo (PINTO, 2010), os grupos de esquerda e a Igreja Católica, lutando principalmente contra o regime autoritário e pela conquista de melhores condições de vida (SADER, 1995).

Para Pereira e Passos (2017), de modo geral, nas décadas de 1960 e 1970 foram realizados também debates históricos sobre mulheres, principalmente, aquelas que não eram ligadas à elite e pertenciam à diferentes grupos étnicos: mulheres negras, indígenas, e do 
'terceiro mundo', as quais denunciavam a sua não representatividade em relação ao 'feminismo branco acadêmico' e, na maioria das vezes, eram submetidas às opressões. Com isso, o feminismo avançou social e teoricamente ao compreender que dentre as mulheres existiam diferenças e particularidades que determinavam 'o que é ser mulher', bem como seus lugares sociais. Um fenômeno de mobilizações denominado por feminismo interseccional, noção introduzida por Kimberlé Crenshaw (2002), no ano de 1989 nos Estados Unidos, passa a ser utilizada enquanto ferramenta para que mulheres atingidas por diferentes tipos de opressão (raça, classe, sexualidade) pudessem entender e falar sobre sua condição.

É importante dizer que com a redemocratização dos anos de 1980, a luta pelos direitos das mulheres torna-se plural e envolve temas como "violência, sexualidade, direito ao trabalho, igualdade no casamento, direito à terra, direito à saúde materno-infantil, luta contra o racismo, e pelas orientações sexuais". (PINTO, 2010, p. 17). No ano de 1984, seria criado o Conselho Nacional da Condição da Mulher $(\mathrm{CNDM})$ e, unido ao Centro Feminista de Estudos e Assessoria (CFEMEA), originou-se a campanha nacional para a inclusão dos direitos das mulheres na nova carta constitucional. Posteriormente, alguns direitos para as mulheres seriam assegurados na Constituição Cidadã, o que significava a "alteração da condição da mulher na Constituição Federal de 1988, que extinguiu a tutela masculina na sociedade conjugal" (SARTI, 2004). Na mesma década, a violência doméstica teve destaque central nos discursos e mobilizações feministas devido ao assassinato de mulheres e absolvição nos tribunais dos assassinos (principalmente seus maridos).

O início da década de 1990 seria marcado por mobilizações de uma nova geração de mulheres, a denominada 'terceira onda feminista', que incluem nos debates a análise da diversidade, da contradição e da produção singular da subjetividade de mulheres (NARVAZ; KOLLER, 2006). Período no qual os debates feministas englobam os estudos Queer, integram a consciência racial (CARNEIRO, 2003) e pós-colonialista (MESSEDER, 2020), além de abarcarem também a teoria crítica e o transnacionalismo. Além disso, foi o momento de disseminação no Brasil das primeiras discussões sobre o feminismo interseccional que Akotirene (2018, p. 14) define como uma forma de instrumentalizar "teóricametodologicamente à inseparabilidade estrutural do racismo, capitalismo e cisheteropatriarcado [...] onde mulheres negras são repetidas vezes atingidas pelo cruzamento e sobreposição de gênero, raça e classe, nos modernos aparatos coloniais." Dessa forma, expande-se as discussões sobre a descriminalização do aborto, a medicalização do corpo da mulher e suas relações com 
a contracepção exclusivamente feminina, a violência contra mulher e as denúncias contra o feminicídio, entre outras temáticas (AKOTIRENE, 2018; bell hooks, 2018; RAGO, 2019).

Segundo Carone (2018), no fim da década de 1990 a luta feminista, de modo geral, adentrou-se ao terceiro setor juntamente com o Estado para aprovar medidas protetoras para as mulheres e ampliar sua participação política, em especial, no combate à violência, principalmente a doméstica e a familiar. Algumas das demandas feministas que se relacionam com essas temáticas foram respondidas por meio da criação dos Conselhos Estaduais da Condição Feminina, do Conselho Nacional dos Direitos da Mulher, das Delegacias de Defesa da Mulher e da criação de agências estatais, com destaque para a Secretaria Especial de Política para as Mulheres (SPM). Apesar da criação desses órgãos, as leis protetivas às mulheres ainda eram incipientes, e somente com o emblemático caso de Maria da Penha Maia que a discussão reverberou em ações no campo legislativo e político, pois a vítima foi alvo de sucessivos atos de violência física e psicológica por parte de seu marido, que tentou assassiná-la em diferentes ocasiões. No ano de 1998, o caso foi levado pela própria vítima à Comissão Interamericana de Direitos Humanos (CIDH) e a Organização dos Estados Americanos (OEA). Finalmente, no ano de 2001, a Comissão responsabilizou o Estado brasileiro por tolerância em relação à violência doméstica contra as mulheres, o que garantiria a constituição de legislação protetiva às mulheres (CARONE, 2018).

No ano de 2006 foi aprovada a Lei Maria da Penha (Lei 11.340/06) que é atualmente considerada como uma das grandes conquistas a favor da mulher no Brasil, e que dispõe sobre mecanismos para coibir a violência doméstica e familiar. Antes de ser promulgada, a maioria dos casos de violência doméstica terminava em arquivamento nas audiências de conciliação ou tipos penais considerados como delitos de menor importância (CONSELHO REGIONAL DE PSICOLOGIA, 2012).

Atualmente, algumas pesquisadoras dos estudos feministas discutem sobre os novos rumos do movimento e acreditam na constituição de uma nova geração de mulheres que em luta estariam organizando a denominada "quarta onda feminista" (NARVAZ; KOLLER, 2006). Nesse contexto, as mobilizações feministas atuais recusam o silenciamento, denunciam abusos e a exploração sexista por meio das redes sociais e também nos espaços acadêmicos, onde se debatem as pautas acerca da cultura do estupro, da representação da mulher na mídia, do combate à homofobia, e também da discussão identitária do movimento de Lésbicas, Gays, Bissexuais, Transexuais e Transgêneros (LGBTT) e pós-identitária (FRANCINI, 2017; TIBURI, 2018; RAGO, 2019).

Barbarói, Santa Cruz do Sul, n. 58, p.<195-217>, jan/jun 2021 


\section{Movimento da luta antimanicomial: conquistas e desafios no âmbito da atenção psicossocial}

O Movimento da Luta Antimanicomial caracteriza-se pela luta por direitos de pessoas que estão em intenso sofrimento psíquico. São mobilizações que combatem a concepção de que o isolamento social, por meio da hospitalização manicomial, é a via de acesso para um suposto tratamento das denominadas loucuras. O movimento antimanicomial parte do pressuposto que as pessoas têm o direito fundamental à liberdade, o direito a viver em sociedade, receber cuidado e tratamento sem que para isto tenham que abrir mão de seu exercício enquanto cidadãos (BRASIL, 2018).

De modo geral, o movimento opõe-se às concepções normativas da psiquiatria do século XVIII e XIX, pautada nos ideais positivistas, nos quais as teorias científicas eram consideravas verdades certas, fixas, definitivas e incontestáveis. Dessa forma, a psiquiatria nascente do final do século XVIII, ao se apropriar do tema da loucura transformou-a em objeto médico compreendido, então, como uma doença da razão, originada no corpo do indivíduo (FOUCAULT, 1972). Para a psiquiatria, os sujeitos considerados "normais" eram capazes de fabricar seus pensamentos e emoções, e controla-los a nível da razão - quem não os fizessem seriam compreendidos como anormais, desajustados e alienados (SERRANO, 1982). Nesse contexto, o nascimento da psicopatologia e da nosologia psiquiátrica permitiu a classificação e nomeação de diferentes tipos de doenças mentais e submeteu o sujeito da loucura às determinações diagnósticas, à tutela médica e ao sequestro e internamento manicomial, que culminava em processos de estigmatização e cronificação de asilados hospitalizados (YASUI, 2010).

No Brasil de fins do século XIX e início do século XX, o sistema manicomial estará pautado no movimento higienista e eugênico que considerava primordial o controle e a extinção em âmbitos sociais dos membros considerados anômalos, desajustados e degenerados, em um processo biopolítico de gerenciamento da população (FOUCAULT, 2002). Assim, baseado no discurso médico, religioso e jurídico, aqueles que se desviassem da norma seriam internados e submetidos ao saber-poder médico que defendia o planejamento da raça, o branqueamento da população brasileira e o controle de gestos, atitudes e comportamentos considerados impróprios. Nos espaços manicomiais o tratamento moral empregado pela psiquiatria higienista era baseado em violentas práticas físicas e psicológicas, à saber: a cadeira giratória, a hidroterapia, os choques insulínicos, as drogas convulsivas, a contenção física por meio da 
denominada camisa de força, posteriormente, o choque elétrico e a lobotomia, assim como, os processos mais recentes de hipermedicalização. (AMARANTE, 2007).

Com o fim da Segunda Guerra Mundial, surgem diversas experiências de reformas psiquiátricas que buscavam desconstruir o pensamento sobre a loucura e as formas de tratá-la. Dentre as diversas experiências, destaca-se a Psiquiatria Democrática italiana protagonizada por Franco Basaglia que politiza tais relações e propõe reformas para a desconstrução do manicômio. No início dos anos de 1970, na cidade de Trieste, Basaglia, juntamente com sua equipe, impulsionou o fechamento dos pavilhões e enfermarias psiquiátricas e criou dispositivos substitutivos ao modelo manicomial (AMARANTE, 1994). Momento de criação dos primeiros Centros de Saúde Mental distribuídos territorialmente, bem como, de implantação de cooperativas de trabalho e de residência para ex-internos que deveriam habitar a cidade por meio de diversas formas de participação e produção social. Basaglia propunha modificações por meio de um processo social complexo de desconstrução do conjunto de aparatos científicos, legislativos e administrativos forjados pela psiquiatria para domínio da loucura. (AMARANTE, 1994; YASUI, 2010).

No Brasil, o Movimento da Reforma Psiquiátrica se iniciou no final da década de 1970, em pleno processo de redemocratização do país. Iniciado no Rio de Janeiro, o Movimento dos trabalhadores em Saúde Mental (MTSM) se tornou uma mobilização nacional imprescindível para que, no ano de 1979 fosse organizado o I Congresso Nacional do MTSM, em São PauloSP. Segundo Bazarghi (2018), no fim da década de 1980 e início da década seguinte, ocorreram dois marcos importantes para o encaminhamento da luta antimanicomial: o II Congresso Nacional do MTSM, na cidade de Bauru-SP, e o I Encontro Nacional da Luta Antimanicomial, na cidade de Salvador-BA. O chamado "Encontro de Bauru", que aproximou usuários e familiares nas mobilizações antimanicomiais, radicalizou a discussão, defendendo o lema "por uma sociedade sem manicômios", momento em que

\footnotetext{
[...] diferentes categorias profissionais, associações de usuários e familiares, instituições acadêmicas, representações políticas e outros segmentos da sociedade questionam o modelo clássico de assistência centrado em internações em hospitais psiquiátricos, denunciam as graves violações aos direitos das pessoas com transtornos mentais e propõe a reorganização do modelo de atenção em saúde mental no Brasil a partir de serviços abertos, comunitários e territorializados, buscando a garantia da cidadania de usuários e familiares, historicamente discriminados e excluídos da sociedade. (BRASIL, 2018, on-line).
}

O encontro também instituiu o dia 18 de Maio como o Dia Nacional da Luta Antimanicomial e, a partir disso, estabeleceu em todo país a ocorrência de atividades culturais, políticas, acadêmicas, esportivas para a promoção de debates contra os preconceitos 
relacionados à loucura. Dessa forma, a participação de novos atores sociais deu ao movimento um caráter intrinsecamente social, fazendo com que "a questão da loucura e do sofrimento psíquico deixasse de ser exclusividade dos médicos, administradores e técnicos da saúde mental para alcançar o espaço das cidades, das instituições e da vida dos cidadãos, principalmente daqueles que as experimentam em suas vidas.” (AMARANTE, 1995 p. 95).

O I Encontro Nacional da Luta Antimanicomial de Salvador-BA, mobilizou inúmeras pessoas e concretizou a organização de um movimento social a nível nacional, incluindo usuários e seus familiares. Naquele evento, inúmeras propostas e discussões foram inseridas para que houvesse a divulgação de informações e promoção de articulações, assim como, foi estabelecido que a cada dois anos aconteceriam encontros nacionais, intercalados anualmente com encontros de usuários e familiares (BAZARGHI, 2018).

Posteriormente, foi organizado o II Encontro Nacional de Usuários e Familiares do Movimento Antimanicomial, que ocorreu em Santos-SP, no mesmo ano, e onde foi elaborado: “A carta de Direitos e Deveres dos Usuários e Familiares dos Serviços de Saúde Mental” que previa o direito ao tratamento em serviços abertos e, sob hipótese alguma, a violação dos direitos de cidadania, materializadas, sobretudo, nas práticas de tortura e violência de manicômios (AMARANTE, 1995).

Outro momento crucial para a Reforma Psiquiátrica e para a Luta Antimanicomial foi a aprovação, depois de doze anos de tramitação, da Lei 10.216/2001, nomeada de "Lei Paulo Delgado", a qual abarca a proteção dos direitos das pessoas em intenso sofrimento psíquico, prevê a substituição progressiva dos manicômios e propõe o redirecionamento do modelo de assistência em saúde mental para os dispositivos da rede de atenção psicossocial. Além disso, ainda estabelece a responsabilidade do Estado no desenvolvimento de políticas de saúde mental no país, por meio do fechamento de hospitais psiquiátricos, da abertura de novos serviços territoriais e da participação social no acompanhamento de sua implementação (YASUI, 2010).

Sob o marco da lei 10.216/01, ocorreu a III Conferência Nacional de Saúde Mental, em Brasília-DF, envolvendo grande participação popular e democrática, em que se discutia diversos temas sobre a complexidade do campo da Reforma Psiquiátrica brasileira: o enfrentamento do estigma, a reorientação do modelo assistencial com garantia de equidade de acesso, os direitos de cidadania como prioridade para a formulação de políticas que fomentem a autonomia dos sujeitos, além da expansão do financiamento e controle social.

Contudo, segundo Amarante (1994), as leis não bastam, sobretudo, é necessário mudar a mentalidade e concepções da população brasileira quando o tema é loucura, assim, faz-se 
essencial transformar atitudes, relações sociais, e para que isso ocorra é importante o envolvimento da sociedade na discussão da Reforma Psiquiátrica. O movimento antimanicomial combate a estigmatização do sujeito em sofrimento psíquico e propõe uma nova relação da sociedade com a loucura, compreendendo o sujeito em sua singularidade, com suas experiências, angústias e desejos. Para que a lógica antimanicomial se firme, é necessário que diversos atores sociais estejam envolvidos no processo complexo e de construção diária e constante para resistir aos estigmas e à manicomialização (YASUI, 2010; AMARANTE, 2007).

Dentre as inúmeras práticas e acontecimentos marcantes que levam à discussão e à participação dos diversos dispositivos e atores sociais é possível citar: a "Marcha dos usuários em Brasília” (2010), o Fórum Gaúcho em Saúde Mental, as associações de usuários, técnicos e familiares (Loucos pela vida), a ocupação "Fora Valencius" (2016), a criação dos blocos e coletivos carnavalescos como "Tá Pirando, Pirado, Pirou!”, "Loucura Suburbana”, "Lokomotiva", as televisões comunitárias (TV Tam Tam, TV Parabolinoica), os programas de rádio (Rádio Tam Tam), os grupos musicais (como Harmonia Enlouquece), o Coral Cênico, os grupos de teatro e as criações de políticas culturais, dentre outros (projeto Loucos pela Diversidade). Por meio dessas iniciativas, vinculadas à dimensão sociocultural da Reforma Psiquiátrica, pretende-se que a discussão extrapole o espaço dos serviços e atinja a sociedade. Cabe sinalizar ainda a existência de inúmeros fóruns e associações de âmbitos nacionais, estaduais e regionais que se mantém ativas e atuantes em defesa de uma sociedade sem manicômios (AMARANTE, 2007).

\section{Uma análise dos movimentos antimanicomial e feminista a partir do paradigma da atenção psicossocial}

Os movimentos antimanicomiais e feministas foram influenciados pelas experiências de mobilizações de grupos e coletivos nos países da Europa e nos Estados Unidos no século XX. E ganharam, no contexto brasileiro pós-ditadura militar, características de luta contra o modelo hegemônico neoliberal e de reivindicação contra as violentas práticas físicas e psicológicas na busca por outras formas de participação social e política, engajada na conquista de direitos e no exercício da cidadania (PEREIRA; PASSOS, 2017). Além disso, é importante ressaltar também que ambos os movimentos irão propor novas formas de relacionamento social, livre das tutelas impostas pela dominação masculina em âmbito patriarcal (TIBURI, 2018) e liberto das amarras do saber-poder psiquiátrico que impõe o isolamento social em hospitais psiquiátricos (YASUI, 2010). 
Pereira e Passos (2017) discutem que os estudos feministas e as construções teóricas da Reforma Psiquiátrica, especialmente quando articulados, trazem diversos pontos em comum. Ambos se colocam frente à problemática da dominação burguesa e patriarcal sobre as mulheres a partir da medicalização e institucionalização de corpos, e que encontra na lógica manicomial saberes e espaços privilegiados. Além disso, o movimento antimanicomial brasileiro já em suas origens demonstrava as convergências de diálogo ao propor um projeto de desinstitucionalização da psiquiatria e, fundamentado no pensamento basagliano, problematizava diversos tipos de opressão existentes na sociedade, em especial a de raça, etnia, classe e a discriminação contra as mulheres. Na carta de Bauru, um dos documentos inaugurais da Luta Antimanicomial no Brasil tem-se que:

\begin{abstract}
O manicômio é expressão de uma estrutura, presente nos diversos mecanismos de opressão desse tipo de sociedade. A opressão nas fábricas, nas instituições de adolescentes, nos cárceres, a discriminação contra negros, homossexuais, índios, mulheres. Lutar pelos direitos de cidadania dos doentes mentais significa incorporarse à luta de todos os trabalhadores por seus direitos mínimos à saúde, justiça e melhores condições de vida. (Movimento dos Trabalhadores de Saúde Mental, Carta de Bauru, 1987).
\end{abstract}

Segundo Amarante (2007), a proposta basagliana guiou o movimento antimanicomial no Brasil e trouxe para primeiro plano a experiência humana ao invés de privilegiar o modelo teórico conceitual da psiquiatria tradicional, pautado na nosografia e em concepções normativas. Assim, Basaglia também permitiu falar sobre singularidades, problemas concretos do cotidiano e problematizar a concepção de que as mulheres possuíam, segundo a psiquiatria, um certo "orgânico louco", afirmação de que as condições biológicas justificariam e naturalizariam supostas desordens como exclusivamente femininas (ZANELLO, 2018).

Contudo, os estudos sobre a relação entre mulheres e saúde mental são escassos e subalternizados no âmbito do movimento antimanicomial, ainda que o tema sobre a psiquiatrização e medicalização de corpos femininos apresente problemáticas pertinentes e atuais (PEREIRA; PASSOS, 2017). Segundo Zanello (2018), o aparato manicomial sempre foi utilizado também para reprimir, normalizar e excluir as diferenças de gênero. Mais especificamente, no início do século XX, quando o movimento feminista dava os primeiros passos, as mulheres começavam a entrar nas universidades e na política, a insurgência feminina foi vista como uma ameaça à ordem social estabelecida e houve diferentes tentativas de repressão para controlar uma suposta "crise da família".

Dessa forma, um dos mecanismos de controle era o poder manicomial que encarcerava mulheres distantes de uma suposta conformidade com os padrões de gênero (ZANELLO, 2018). Mulheres que rotuladas como loucas, ora para desqualificar um discurso ora para exclui-las da 
sociedade, eram também submetidas ao processo de manicomialização (CUNHA, 1989). A atualidade não se faz diferente e os processos de psiquiatrização do corpo da mulher ganham contornos pautados em rotulações diagnósticas e prescrição de medicamentos psicofarmacológicos que pretendem controlar a considerada condição "orgânica da loucura feminina" (PEREIRA; PASSOS, 2017).

Nesse contexto de discussão sobre a histórica psiquiatrização do corpo feminino e de debates sobre as convergências de luta por direitos de atores sociais nas mobilizações antimanicomiais e feministas, pretende-se analisar as transformações produzidas, assim como, apontar alguns desafios a serem alcançados por ambos os movimentos. Dessa forma, pautados nas diferentes dimensões do paradigma da Atenção Psicossocial em Saúde Mental, conforme proposto por Amarante (2007), pretende-se introduzir um debate sobre as transformações em âmbitos teórico-conceituais, socioculturais, político-jurídicos, sendo estas ferramentas utilizadas como analisadores da transformação paradigmática hegemônica manicomial e patriarcal que se pretende superar.

No primeiro âmbito de transformação, denominado teórico-conceitual, o movimento antimanicomial propõe a superação dos discursos e práticas de saber-poder da psiquiatria para a construção de outro olhar para o sujeito em sofrimento psíquico. Assim, a partir de inspirações basaglianas, com propostas de colocar a doença mental entre parênteses para entrar em contato com a existência-sofrimento do sujeito, as mobilizações antimanicomiais propõem a construção de espaços e dispositivos de cuidado em liberdade. Movimentações que permitiram o questionamento em relação a determinação de diagnósticos, disponibilizados em manuais psiquiátricos (MARTINHAGO; CAPONI, 2019), a problematização das prescrições de medicamentos psicofarmacológicos como única estratégia de tratamento em saúde mental (FREITAS; AMARANTE, 2017), além do fechamento de mais de 80 mil leitos em hospitais psiquiátricos e a abertura de inúmeros serviços substitutivos à internação manicomial em âmbito territorial (BRASIL, 2015).

De forma semelhante, no âmbito das transformações teórico-conceituais, o movimento feminista propõe a construção de um novo olhar e compreensão da mulher contemporânea, contemplando as especificidades que envolvem a interseccionalidade entre gênero, raça, classe social, orientação sexual e a plasticidade das condições de aparência física e idade (AKOTIRENE, 2018; TIBURI, 2018). Nesse contexto, o pensamento feminista caminhou para o rompimento com a compreensão unívoca de mulher e fortaleceu discussões sobre a existência da diversidade de condições singulares que afetam mulheres negras, indígenas, latino- 
americanas, pobres, deficientes, entre outras especificidades. E na conquista por amplos espaços de debates e, apesar da pluralidade de abordagens e das divergentes vertentes teóricas feministas que disputam espaços nos debates acadêmicos, o movimento caminha na produção de discussões éticas-conceituais sobre o feminismo para a construção de um "mundo mais filógino" (RAGO, 2019). Contudo, ainda que as mulheres tenham conquistado direitos políticos, acesso à educação, igualdade de direitos no casamento, permanecem discursos e práticas de desigualdades de gênero que submetem mulheres, em diferentes contextos, às inúmeras desvantagens em relação aos homens na sociedade atual (MIGUEL; BIROLI, 2014).

No segundo âmbito de transformação relacionado aos aspectos socioculturais, ambos os movimentos carregam a característica da interseccionalidade: o movimento antimanicomial inclui a participação de novos atores sociais, fazendo com que a questão da loucura e do sofrimento psíquico deixe de ser exclusividade dos médicos, administradores e técnicos da saúde mental para alcançarem a vida dos cidadãos, o espaço das cidades e o cuidado por familiares, incluindo uma gama de atores sociais (YASUI, 2010). Por sua vez, o movimento feminista, inicialmente composto por mulheres da camada média ou elite branca que defendiam seu direito ao voto, seu lugar na sociedade e no mercado de trabalho, ganha adesão nas mobilizações contra a exploração da classe social, contra as opressões de raça, demarcando as diferenças e particularidades do "ser mulher" na contemporaneidade.

Assim, o movimento feminista avança em diversos espaços sociais conscientizando mulheres sobre o sexismo institucionalizado, disseminando discursos e práticas sobre a igualdade de gênero nas redes sociais, televisão, literatura, rádio, cinema, o que poderá culminar na constituição de novas subjetividades feministas (RAGO, 2019). No âmbito das mobilizações antimanicomiais, as mudanças socioculturais embora tenham avançado não foram suficientes para o enfrentamento da tão arraigada cultura do manicômio (AMARANTE, 2019), ainda presente na sociedade brasileira e que se expande em tempos de retrocesso, no qual silenciar e excluir supostos degenerados parece ser a tônica.

$\mathrm{Na}$ dimensão jurídica-política, a aprovação de leis antimanicomiais e feministas - "Lei Pedro Delgado" e "Lei Maria da Penha" - significou conquistas importantes. A lei 10.216/01, conhecida como Lei da Reforma Psiquiátrica, proposta pelo Deputado Pedro Delgado, além de outras portarias ministeriais, assegurou a elaboração de Políticas Públicas de Saúde Mental no Brasil nos últimos anos. E possibilitou a implementação de uma rede de serviços substitutivos à internação manicomial que proporciona estratégias intersetoriais de atenção e cuidado singular dos usuários em intenso sofrimento psíquico (AMARANTE, 2007). Contudo, em 
tempos sombrios, os retrocessos atuais no campo da Saúde Mental marcam a contrarreforma com a aprovação de legislações que preveem a contratação de 12 mil leitos em comunidades terapêuticas, o financiamento para a ampliação de leitos em hospitais psiquiátricos, a retomada da possibilidade de internação de crianças e adolescentes e a retirada do termo rede substitutiva à internação manicomial para seu incentivo e valorização, entre outros aspectos (FERRAZZA; ROCHA, 2020).

Da mesma forma, no âmbito das lutas feministas foram inúmeras as conquistas jurídicopolíticas: o direito ao voto, a conquista do mercado de trabalho, o direito ao divórcio, a possibilidade para se estudar e se formar em uma profissão, a representatividade nos espaços políticos e sociais, o surgimento e uso do anticoncepcional que permitiu maior controle sobre a natalidade e proporcionou liberdade sexual para mulheres (TIBURI, 2018; MIGUEL; BIROLI, 2014). Contudo, são inúmeros os desafios a serem alcançados, com destaque para alguns importantes pontos: o enfrentamento do racismo e sexismo que condenam mulheres negras a exclusão e marginalização, a superação da desigualdade salarial entre homens e mulheres, o enfrentamento das altas taxas de violência de gênero e feminicídio, a luta contra a baixa representatividade das mulheres no âmbito político, a garantia da distribuição gratuita nos serviços de saúde de métodos contraceptivos e contra a transmissão de infecções sexualmente transmissíveis, os enfrentamentos contra discursos e práticas lesbofóbicas e a elaboração de debates e políticas para a descriminalização do aborto no Brasil (CARNEIRO, 2003; MIGUEL; BIROLI, 2014).

Nessa perspectiva, é importante ressaltar que tanto o movimento feminista quanto o antimanicomial levam à público as demandas específicas de grupos que antes ficavam encobertas e adormecidos na esfera privada. E mediante as experiências compulsórias de clausura, seja do ambiente doméstico destinado às mulheres ou institucional determinado aos loucos, as discriminações sofridas e os estigmas impostos são denunciados e direitos são reivindicados na esfera pública por meio de marchas, caminhadas, mobilizações e paradas. $\mathrm{O}$ deslocamento, do privado para o público, propiciou modificações nos aparatos acadêmico, técnico, legislativo, político e social acerca dos dois grupos, seja nas políticas públicas e jurídicas ou pela reconfiguração de discursos e práticas socioculturais.

É possível observar também que conforme os 'novos movimentos' evoluem em determinados contextos históricos, tais mobilizações possibilitam transformações de temas a serem discutidos, bem como, desafios a serem enfrentados. No início do movimento feminista a preocupação era principalmente a emancipação feminina, as feministas atuais questionam a 
cisheteronormatividade, o sexismo institucionalizado, o preconceito racial, o feminicídio, a cultura do estupro e a homofobia. De forma semelhante, o movimento da Reforma Psiquiátrica, ao desconstruir os discursos e práticas de saber-poder da psiquiatria sobre a loucura, propunha a princípio o fechamento de manicômios. Atualmente, o movimento se reconfigura para enfrentar a lógica manicomial e medicalizante ainda presente em serviços substitutivos à internação hospitalar e para superar retrocessos no âmbito das Políticas Públicas de Saúde Mental que tencionam também segmentos reacionários da sociedade civil.

\section{Considerações finais}

O panorama histórico dos movimentos sociais feminista e antimanicomial, presente neste estudo, permitiu refletir que ambos possuem características próprias, mas que em comum fazem ecoar suas vozes na luta contra a lógica hegemônica marcada pela opressão patriarcal e controle manicomial. A luta daqueles movimentos é a de liberdade, de reconhecimento dos direitos e de garantia de oportunidades, na qual mulheres e/ou pessoas em intenso sofrimento psíquico tenham autonomia para decidir sobre suas vidas e seus corpos. Por meio das reflexões propostas nesse trabalho observa-se que os dois movimentos em questão se estruturaram em contextos históricos e sociais muito parecidos, e possuem uma natureza complexa, uma vez que exigem mudanças culturais, jurídicas, técnicas e políticas, perpassam questões de raça, gênero e classe, na busca por autonomia e pelo exercício da cidadania. Também almejam superar estigmas e propõem novas formas de relacionamento e lugar na agenda política, a fim de decidir sobre a vida desvencilhando-se das construções sociais propostas pelo patriarcado e pelo saber psiquiátrico. Movimentos que foram se transformando com o passar do tempo, de acordo com as demandas dos grupos e superação de paradigmas, em diversos contextos sócio-históricos.

No Brasil atual, marcado por um governo reacionário que dissemina discursos de ódio às minorias sociais que continuam a vivenciar a exclusão, o racismo, o machismo e a misoginia, as duras conquistas de direitos após a Ditadura Militar, que culminaram em importantes Políticas Públicas, também estão ameaçadas e outros tantos aspectos deixam de ser pauta de debate político e governamental. Nessa perspectiva, considera-se que a análise histórica da constituição dos movimentos antimanicomiais e feministas permite verificar que as transformações se deram por meio da luta organizada nas ruas e protagonizada por diferentes atores sociais, o que culminou nas modificações da vida pessoal de inúmeras mulheres e sujeitos em intenso sofrimento psíquico. Mobilizações que impulsionaram inclusive a proposição de 
leis que impediam a naturalização da violência física e psicológica contra mulheres e impossibilitou o generalizado encarceramento de pessoas em intenso sofrimento psíquico.

Conforme aponta Gohn (2011, p. 336), espera-se que ambos os movimentos sociais possam investir na "resistência ao velho que oprime ou na construção do novo que liberte". Dessa forma, à guisa de conclusão, considera-se a necessidade de constituir novas formas de pensar sobre nossa condição histórica, com intuito de que isso possibilite a criação de estratégias de reinvenção e recriação constante de coletivos de luta e que promovam movimentos de resistências aos poderes instituídos que submetem mulheres e sujeitos em sofrimento psíquico, com objetivos de constituir mudanças e responsabilização social para que os absurdos tolerados por parcela considerável da sociedade não se reproduzam.

\title{
FEMINIST AND ANTI-ASYLUM MOVEMENT: AN ANALYSIS OF FIGHTS FOR RIGHTS IN CAPITALIST-PATRIARCHAL SOCIETY
}

\begin{abstract}
The present study aims to draw a parallel between the feminist and the anti-asylum movements looking for convergence and divergence points between both, in order to verify their possible articulations. To do so, through bibliographic review, it seeks to contextualize the social movements and carry out the historical analysis of both, in order to clarify their motivations, ways of acting in the fight for rights and meeting the demands of the subjects involved with the pretensions of achieving social transformations. This way, this paper discusses the confluences and divergences between the feminist and anti-asylum movement, in an attempt to broaden and build the academic debate on the subject, which changes daily, in a democratic and dialectical way. By way of conclusion, it is considered the need to constitute new ways of thinking about our historical condition, in order to allow the creation of strategies of constant reinvention recreation of fight collectives and that it promotes resistance movements against instituted powers which subject women and individuals in psychological distress, with the goal to constitute changes and social responsability so that the absurdities tolerated by a considerable part of society are not reproduced.
\end{abstract}

Keywords: social movements; feminisms; anti-asylum fight; normalization of life.

\section{MOVIMIENTO FEMINISTA Y MOVIMIENTO CONTRA EL ASILO: UN ANÁLISIS DE LA LUCHA POR LOS DERECHOS EN UNA SOCIEDAD CAPITALISTA- PATRIARCAL}

\section{Resumen}

El presente estudio tiene como objetivo comprender las posibles conexiones entre el movimiento feminista y el movimiento contra el asilo buscando puntos de convergencia y divergencia entre ambos, con el fin de verificar sus posibles articulaciones. Para esto, a través de la revisión bibliográfica, se busca contextualizar los movimientos sociales y realizar el análisis histórico de ambos para aclarar sus motivaciones, formas de actuar en la lucha por los derechos y atender las demandas de los sujetos involucrados con las pretensiones de logrando transformaciones sociales. De esta manera, este trabajo discute las confluencias y divergencias 
entre el feminismo y el movimiento contra el asilo, en un intento por ampliar el debate académico sobre el tema, que cambia a diario, de manera democrática y dialéctica. En conclusión, consideramos la necesidad de establecer nuevas formas de pensar sobre nuestra condición histórica, con la intención de posibilidad de creación de estrategias de reinvención y recreación constante de la lucha colectiva y que promueva movimientos de resistencia a los poderes establecidos que someten a las mujeres y individuos en malestar psicológico, con fines constitutivos de cambios y responsabilidad social para que no se reproduzcan los absurdos tolerados por una parte considerable de la sociedad.

Palabras-clave: movimientos sociales; feminismos; lucha contra el asilo; normalizacion de la vida.

\section{REFERÊNCIAS}

AKOTIRENE, Carla. O que é interseccionalidade? Belo Horizonte: Letramento:

Justificando, 2018.

AMARANTE, Paulo. Asilos, alienados e alienistas: pequena história da psiquiatria no Brasil. In: Psiquiatria social e reforma psiquiátrica. Rio de Janeiro: FIOCRUZ, 1994.

Loucos pela vida: a trajetória da reforma psiquiátrica no Brasil. Rio de Janeiro: FIOCRUZ, 1995.

Saúde Mental e Atenção Psicossocial. Rio de Janeiro: Editora Fiocruz, 2007.

BAZARGHI, Natalia. A. História, memória e luta: Trajetórias na/da Reforma Psiquiátrica Brasileira. 195 f. Tese de doutorado (Programa de Pós-Graduação em Psicologia e Sociedade). Universidade Estadual Paulista, Faculdade de Ciências e Letras, Assis, 2018.

BRASIL, Ministério da Saúde. Biblioteca Virtual em Saúde. 18/05 Dia Nacional da Luta Antimanicomial, 2018.

BRASIL. Ministério da Saúde. Lei no 10.216, Legislação Federal, de 06 de abril de 2001. Dispõe sobre a proteção e os direitos das pessoas portadoras de transtornos mentais e redireciona o modelo assistencial em saúde mental. Presidência da República, Brasília, DF, 1998. Disponível em: http://www.planalto.gov.br/ccivil_03/leis/leis_2001/110216.htm. Acesso em: 14 jun. 2019.

BRASIL. Ministério da Saúde. Nota Técnica n 11/2019-CGMAD/DAPES/SAS/MS. Brasília, DF. Disponível em: 〈http://pbpd.org.br/wp-content/uploads/2019/02/0656ad6e.pdf〉. Acesso em: 11 jun. 2019.

CAMPOI. Isabela Candelora. Mulheres na História: apontamentos para compreender a opressão. Jornal Psicologia em Foco, Maringá, n. 40, p.11, jan-abr. 2019.

CARONE, Renata Rodrigues. A atuação do Movimento Feminista no Legislativo Federal: caso da Lei Maria Da Penha. Revista Lua Nova, São Paulo, n. 105, p. 181-216, 2018. Disponível em: <https://www.scielo.br/pdf/ln/n105/1807-0175-ln-105-181.pdf>. Acesso em: 31 jul. 2019.

CARNEIRO, Sueli. Mulheres em movimento. Estudos avançados. São Paulo, v. 17, n. 49, p. 117-132, 2003

Barbarói, Santa Cruz do Sul, n. 58, p.<195-217>, jan/jun 2021 
CRENSHAW, Kimberlé. Documento para o encontro de especialistas em aspectos da discriminação racial relativos ao gênero. Revista Estudos Feministas, Florianópolis , v. 10, n. 1, p. 171-188, 2002. Disponível em:

<http://www.scielo.br/scielo.php?script=sci_arttext\&pid=S0104-

026X2002000100011\&lng=en\&nrm=iso>. Acesso em: 20 Mai. 2020.

COIMBRA, Cecília; NASCIMENTO, Lívia Maria. Movimentos sociais e sociedade de controle. In: TEDESCO, Silvia; NASCIMENTO, Lívia Maria. Ética e subjetividade: novos impasses no contemporâneo. Sulina, 2012.

CONSELHO FEDERAL DE PSICOLOGIA. Manifesto de Bauru. II Congresso Nacional de Trabalhadores em Saúde Mental, 1987. Disponível em: < https://site.cfp.org.br/wpcontent/uploads/2017/05/manifesto-de-bauru.pdf >. Acesso em: 14 jun. 2019.

. Referências técnicas para atuação de psicólogas (os) em Programas de Atenção à Mulher em situação de Violência. Brasília: CFP, 2012.

CUNHA, Maria Clementina. Loucura, gênero feminino: as mulheres do Juquery na São Paulo do início do século XX. Revista Brasileira de História, v. 9, n. 18, p. 121-144, 1989.

DIAZ, Fernando Sobhie. Os movimentos sociais na reforma psiquiátrica: o "novo" na história da psiquiatria do Brasil. Tese (Doutorado em História das Ciências e da Saúde) Fundação Oswaldo Cruz, 2008.

FRANCHINI, B. S. O que são as ondas do feminismo? Revista QG Feminista, 2017. Disponível em: <https://medium.com/qg-feminista/o-que-s\%C3\%A3o-as-ondas-dofeminismo-eeed092dae3a>. Acesso em: 18 set.2019.

FERRAZZA, Daniele de Andrade; ROCHA, Luiz Carlos. Psicologia e políticas públicas: apontamentos sobre os desafios da atenção e cuidado aos usuários de álcool e outras drogas. In: BORGES, Roselania Franciscone; ZANIANI, Ednéia. Psicologia e Políticas Públicas: Perspectivas e desafios para a formação/atuação. Maringá: Eduem, 2020.

FREITAS, Fernando; AMARANTE, Paulo. Medicalização em psiquiatria. Rio de Janeiro: Editora Fiocruz, 2015.

FOUCAULT, Michel. História da loucura na idade clássica. São Paulo: Perspectivas, 1972.

Em defesa da sociedade: curso no College de France (1975-1976). São Paulo:

Martins Fontes, 1999.

Vigiar e punir: nascimento da prisão. Tradução de Raquel Ramalhete. Petrópolis:

Vozes, 36, 2009.

GONH, Maria da Glória. Movimentos sociais na contemporaneidade. Revista Brasileira de Educação, v. 16, n. 47, maio-agosto de 2011.

Movimentos sociais no início do século XXI: antigos e novos atores sociais.

Petrópolis: Vozes, 2003.

Barbarói, Santa Cruz do Sul, n. 58, p.<195-217>, jan/jun 2021 
Teoria dos movimentos sociais: paradigmas clássicos e contemporâneos. São Paulo: Edições Loyola, 1997.

hooks, bell. O feminismo é para todo o mundo: políticas arrebatadoras. Rio de Janeiro: Rosa dos Tempos, 2018.

JESUS, Jaqueline Gomes de. Psicologia social e movimentos sociais: uma revisão contextualizada. Psicologia e Saber Social, v. 1, n. 2, p. 163-186, 2012.

PEREIRA, Melissa de Oliveira Pereira; PASSOS, Rachel Gouveia. Luta Antimanicomial e Feminismos: Discussões de gênero, raça e classe para a reforma psiquiátrica brasileira. Rio de Janeiro: Autografia, 2017.

PINTO, Céli Regina Jardim. Feminismo, história e poder. Revista Sociologia Política, Curitiba, v. 18, n. 36, p. 15-23, jun. 2010. Disponível em: <

https://www.scielo.br/pdf/rsocp/v18n36/03.pdf >. Acesso em: 23 mai. 2019.

MARTINHAGO, Fernanda; CAPONI, Sandra. Controvérsias sobre o uso do DSM para diagnósticos de transtornos mentais. Physis: Revista de Saúde Coletiva, Rio de Janeiro, v. 29, n. 2, 2019.

MESSEDER, Suely. A pesquisadora encarnada: uma trajetória decolonial na construção do saber científico blasfêmico. In: HOLLANDA, Heloísa Buarque de. Pensamentos feminista hoje: perspectivas decoloniais. Rio de Janeiro: Bazar do Tempo, 2020.

MIGUEL, Luis Felipe; BIROLI, Flavia. Feminismo e política: uma introdução. São Paulo: Boitempo, 2014.

NARVAZ, Martha Giudice; KOLLER, Silvia Helena. Metodologias feministas e estudos de gênero: articulando pesquisa, clínica e política. Revista Psicologia em Estudo, v. 11, n. 3, p. 647-654, 2006.

RAGO, Margareth. "Estar na hora do mundo": subjetividade e política em Foucault e nos feminismos. Interface (Botucatu), Dossiê: Biopolítica e governamentalidade em Saúde, 2019.

. "Feminizar é preciso: por uma cultura filógina". São Paulo em Perspectiva: Revista da Fundação Seade, São Paulo, v. 15 n. 3, p. 58-66, 2001.

SADER, Emir. Quando novos personagens entraram em cena: experiências falas e lutas dos trabalhadores na Grande São Paulo. Rio de Janeiro: Paz e Terra, 1995.

SARTI, Cynthia Andersen. O feminismo brasileiro desde os anos 1970: revisitando uma trajetória. Revista de Estudos Feministas. Florianópolis: v. 12, n. 2, p.35-50, maio-agosto, 2004.

SERRANO, Alan Indio. O que é Psiquiatria Alternativa. São Paulo? Editora Brasiliense, 1982. 
SCHERER-WARREN, Ilse. Movimentos sociais: um ensaio de interpretação sociológica. Florianópolis: UFSC, 1989.

TIBURI, Márcia. Feminismo em comum: para todas, todes e todos. Rio de Janeiro: Rosa dos Tempos, 2018.

TILLY, Charles. Movimentos sociais como política. Revista Brasileira de Ciência Política, Brasília: n. 3, p. 133-160, janeiro-julho, 2010.

ZANELLO, Valeska. Saúde mental, gênero e dispositivos: cultura e processos de subjetivação. Curitiba: Appris, 2018.

ZAPPA, Regina; SOTO, Ernesto. 1968: Eles só queriam mudar o mundo. São Paulo: Editora Zahar, 2018.

YASUI, Silvio. Rupturas e encontros: desafios da Reforma Psiquiátrica Brasileira. Rio de Janeiro: Editora Fiocruz, 2010.

Data de recebimento: $25 / 05 / 2020$

Data de aceite: 08/11/2020

\section{Sobre as autoras:}

Alessandra Rodrigues Sardeto atua como Psicóloga Clínica em Maringá. Possui graduação em Letras pela Universidade Estadual de Maringá (UEM) e graduação em Psicologia, pelo Centro Universitário Ingá. Endereço Eletrônico: alessandrasardeto@gmail.com

Natalia Bazarghi possui graduação e mestrado em Psicologia pela Universidade Estadual de Maringá (UEM) e doutorado em Psicologia pela Universidade Estadual Paulista (Unesp/Assis). Trabalha como professora universitária. Endereço Eletrônico: nanabarzaghi@hotmail.com

Daniele Andrade Ferrazza é professora do Programa de Pós-Graduação e da Graduação em Psicologia da Universidade Estadual de Maringá (UEM). Doutora e mestre pela Universidade Estadual Paulista- Unesp/ Assis-SP. Endereço Eletrônico: danieleferrazza@yahoo.com.br 